Title: A call for professional collaboration to address ethical challenges in nephrology

\title{
Authors
}

1. Dominique E. Martin, PhD, School of Medicine Deakin University, Geelong Waurn Ponds Campus, Locked Bag 20000, Geelong, VIC 3220, Australia.

2. David Harris, MD, University of Sydney at Westmead Hospital, Westmead, NSW 2145, Australia.

3. Vivekanand Jha, MD, George Institute for Global Health, UNSW, New Delhi, India; University of Oxford, Oxford, UK and Manipal Academy of Higher Education, Manipal, India

4. Luca Segantini, International Society of Nephrology, Rue des Fabriques 1, B1000 Brussels, Belgium; European Society for Organ Transplantation - ESOT c/o ESOT, Riviera Mugnai 8/24, 35137 Padova, Italy

5. Richard A Demme, MD, Renal Division and Department of Medical Humanities and Bioethics, University of Rochester School of Medicine, Rochester, NY 14642 USA

6. Thu H. Le, MD, Renal Division, University of Rochester School of Medicine, Rochester, NY 14642 USA

7. Laura McCann, MSW, American Society of Nephrology, 1401 H Street, NW, Suite 900, Washington, DC 20005, USA

8. Jeff M. Sands, Renal Division, Emory University School of Medicine, Atlanta, GA 30322 USA

9. Gerard Vong, DPhil, Center for Ethics, Emory University, Atlanta, GA, 30322 USA

10. Paul Root Wolpe, PhD, Center for Ethics, Emory University, Atlanta, GA, 30322 USA 
11. Monica Fontana, MA, European Renal Association - European Dialysis and Transplant Association, Via XXIV Maggio 38, I-43123 Parma, Italy

12. Gerard M London, MD, Manhes Hospital , Nephrology Department GEPIR, 8 rue Roger Clavier, 91700 Fleury-Mérogis, France

13. Bert Vanderhaegen, MA, University Hospital, Corneel Heymanslaan 10, B9000 Gent, Belgium

14. Raymond Vanholder, PhD, Nephrology Section, Deparment of Internal Medicine, University Hospital, Corneel Heymanslaan 10, B9000 Gent, Belgium 


\begin{abstract}
The American Society of Nephrology (ASN), the European Renal Association - European Dialysis and Transplant Association (ERA-EDTA) and the International Society of Nephrology (ISN) have formed a Joint Working Group on Ethical Issues in Nephrology to facilitate collaboration on efforts to address current and emerging challenges for nephrologists; this paper represents the first part of this project. Ten broad areas of ethical concern in nephrology are described in order to highlight the need for ethical analysis of specific issues, and for training and development of guidance tools to support clinicians in practicing ethically and in contributing to ethical policy making. Collaborative action on these challenges is advocated to achieve equity in access to ESKD care, avoid futile dialysis, safely reduce costs of dialysis, facilitate shared decision-making in ESKD care, support donor evaluation and decision-making in living kidney donation, encourage priority setting in kidney disease prevention and care, address the ethical implications of genetic kidney diseases, advocate responsibly for kidney health, and to manage conflicts of interest in nephrology.
\end{abstract}

\title{
Introduction
}

Despite extensive research investigating factors influencing equity of access to nephrology care, ${ }^{1-6}$ and the publication of several papers recognizing the wide range of ethical issues that nephrologists confront in their daily practice, ${ }^{7-29}$ there is limited clear and actionable guidance available to clinicians on how to manage common and impactful ethical issues in nephrology. To address this, in 2018 the American Society of Nephrology (ASN), the European Renal Association - European Dialysis and Transplant Association (ERA-EDTA) and the International Society of Nephrology (ISN) formed a Joint Working Group on Ethical Issues in Nephrology. The group aims first to highlight several important challenges of 
longstanding or emerging ethical concern for clinicians and second, to support development of tools to guide ethical decision-making in clinical practice. In this paper, we address the first aim and strive to motivate action on the second aim. We do so by describing some issues that have been identified by this group as priorities for further ethical exploration and explaining the potential value of ethical training and guidance tools to manage these. We focus intentionally on the role of health professionals in addressing these issues while acknowledging that engagement of other stakeholders such as patients and policy makers, and non-stakeholders such as ethicists and social scientists in collaborative action will be essential to support ethical policy and practice.

\section{Scope of this review}

The list of selected issues includes those on which ethical work by the three societies will be prioritised. Health professionals and other stakeholders face many additional challenges which are not itemised in the list or detailed in this paper, including problems, practices and policies that have significant ethical implications, such as the costs of accessing screening and preventative care for kidney disease in the absence of universal coverage, issues in paediatric decision-making, or conflicts of interest in pharmaceutical prescribing.

Ethical issues in healthcare commonly align with concerns about decision-making, fairness, prevention of harm and promotion of the wellbeing of individuals and communities. Such issues require unique considerations in the local context, and responses must engage with local ethical and social priorities, values, preferences and frameworks for decision-making. Key differences such as whether public funding is provided for dialysis have a significant impact on ethical decision-making and priorities for ethical action within countries. Clinical ethics is often case-specific, and general principles and ideas must be applied according to the 
specifics and dynamics of each situation. On the other hand, other aspects are universal. By promoting and facilitating international discussion and collaboration, the global professional community may reach an understanding of fundamental ethical values that underpin clinical practice and ensure that ethical considerations inform international collaborative research on issues in clinical practice and health policy. Accordingly, this paper is not intended to provide in-depth ethical analysis on particular ethical issues, nor to outline specific practical strategies or recommendations for resolution of ethical issues in particular contexts. It is hoped that this paper will inspire work not only on the issues selected for action by the international working group, but also on other issues that may reflect urgent challenges for stakeholders in particular regions, countries or communities.

\section{Identifying challenges}

The working group was convened by leaderships of the three societies, as the paper is intended to constitute a call to action within each of the societies. Selected members include societal executive officers and nephrologists who have served on societal ethics committees, and individuals with ethics expertise. This membership was not intended to provide a globally demographic representation of nephrologists but rather to draw on the knowledge of society leaders regarding topical ethical issues discussed informally within their societies in recent years.

An introductory review of the literature was performed to identify potential issues of interest pertaining to dialysis, transplantation, and general nephrology. ${ }^{30}$ These issues were considered in the light of discussions held during an ISN summit on ESKD in Sharjah, the United Arab Emirates, in March 2017. ${ }^{31}$ In May 2018, the working group discussed and refined the preliminary list of potential issues and selected a set of priority ethical challenges by consensus. These topics were chosen because they reflect concerns that are common to 
members of the three societies, and thus priorities for collaborative work. Two additional topics were added following feedback from reviewers on an earlier version of this manuscript.

The chosen issues are presented in Box 1 in no particular order. The set covers a range of interconnected issues concerned with improving global kidney health and the quality of life of people and communities affected by kidney disease. It is hoped that sketching these topics of ethical concern will stimulate discussion on how to improve the ethical framework around kidney care in various settings, and engage multiple stakeholders across regions..

\section{Box 1 - Ethical challenges}

1. Achieving equity in access to integrated ESKD care

2. Setting priorities in kidney disease prevention and care

3. Avoiding futile or overly burdensome dialysis treatment

4. Supporting shared decision-making about ESKD care

5. Reducing the cost of dialysis care without compromising quality

6. Preventing organ trafficking and transplant "tourism"

7. Evaluating the risks and outcomes of living kidney donation

8. Addressing the ethical implications of genetic kidney diseases

9. Advocating responsibly for kidney health

10. Managing conflicts of interest in nephrology

Each challenge should be considered in the context of other health and social priorities in a given country/society.

\section{Achieving equity in access to integrated ESKD care}

Equity in health refers to the absence of inequalities or differences that are avoidable, unnecessary and unfair. ${ }^{32}$ Inequalities of potential concern in ESKD care may include not only differences in access to existing services, but also differences in clinician training, regional standards of existing facilities and resources, and degree of government support, among others. ${ }^{31}$ Inequities in access to integrated ESKD care, including dialysis, 
transplantation, and comprehensive conservative and supportive care, are widespread around the world and within many countries. ${ }^{2,6,31}$ Limited availability of kidney replacement therapies (KRTs) and access to available resources are primarily influenced by socioeconomic realities, rather than clinical factors. In some cases, race, gender or citizenship status may determine or strongly influence access. ${ }^{4,5,33-35}$ Criteria used to allocate health resources that are intended to promote greater utility of outcomes from use of KRTs may exacerbate health inequities by favouring those who are already in better health as a result of more privileged access to healthcare. While efforts to increase the availability of resources and to address barriers to access are essential in reducing inequities and improving health outcomes for all, ${ }^{31}$ in the absence of sufficient resources clinicians and policy makers must strive to ensure that resources are allocated so as to promote health equity. Determining frameworks for decision-making and criteria to guide allocation requires careful attention to the values and preferences of the populations among which resources will be allocated, and to the broader context of their social and healthcare systems and priorities. ${ }^{1,14,22}$

Although ethical issues in the allocation of organs for transplantation have received considerable attention, equity of access to transplantation services has received far less scrutiny. While the availability of a suitably matched kidney is essential for patients with ESKD in need of transplantation, many other factors underpin the inequities observed in rates of kidney transplantation at the local and international levels. ${ }^{6,33-5}$ For example, when transplant programs are introduced, particularly in countries that lack universal health coverage, poorer members of society are often excluded due to financial barriers, and despite the fact that performing and maintaining a kidney transplant is often less expensive than providing dialysis in the long run. Financial barriers also exclude the poor from access to dialysis services, with more than two million people, mostly in low and low-middle income 
countries (LMICs) estimated to have died in 2010 as a result of lack of access to dialysis. ${ }^{2}$ Even when the costs of dialysis care are substantially covered by insurance, related healthcare costs and social barriers to care may underpin a high rate of mortality in poorer populations. $^{36}$

Health professionals play an important role in promoting equity of access to dialysis and transplantation services, as well as to conservative or palliative care services. In particular, they can assist in reducing barriers to access by promoting development of transplant and dialysis services in public rather than private facilities; ensuring development of equitable and transparent frameworks for allocation of organs from deceased donors or for rationing of dialysis resources when necessary; supporting timely discussion of and referral for transplantation or conservative care where available and appropriate; supporting patients to discuss opportunities for living donation with potential donors; and facilitating a dialogue between patients and their families about conservative or palliative care as an alternative to dialysis.

Ethical issues may arise when nephrologists make a clinical judgement that a patient would not benefit sufficiently from transplantation or dialysis to justify use of a donated kidney or dialysis services, or to justify the burdens for patients associated with transplantation or dialysis. Clinical decision-making about suitability for KRT may be subject to unrecognized biases, ${ }^{33,37}$ or influenced by financial conflicts of interest, for example when nephrologists or providers have a financial interest in retaining patients on dialysis rather than referring them for transplantation or conservative care. ${ }^{1,7,38,39}$ This can occur when the design of healthcare systems and/or funding for dialysis and transplantation is such that nephrologists, nephrological units or hospitals may earn more by providing dialysis care to a patient than in 
providing post-transplant care. Such interests also influence modality choice - for example, preference may be given to in-center dialysis rather than home hemo- or peritoneal dialysis if a nephrologist has a financial interest in the centre or receives higher payments for providing in-centre care.

The development of practice guidelines, including ethical guidelines for allocation of resources when rationing is required, will support transparent, evidence-based decisionmaking, help to reduce inequities in access to KRTs, and reduce the risk of moral distress for physicians. ${ }^{40-42}$

\section{Priority setting in kidney disease prevention and care}

Priority setting for research in kidney disease has been explored,${ }^{43}$ but much work still needs to be done on priority setting for clinical practice. ${ }^{22}$ This is particularly a concern for health policy makers and health professionals in LMICs where dialysis and/or transplantation programs are currently being introduced that may entail long term, potentially catastrophic costs to health systems and/or patients. Health authorities, policy makers and the nephrology community must consider the implications of investing in ESKD treatment, particularly high cost KRTs, when this may occur at the expense of investment in treatment of other public health priorities. In high income countries, the introduction of high cost, novel therapies may create similar dilemmas for policy makers or insurance providers when determining whether to subsidize therapy for patients, and for clinicians supporting patients to make decisions about treatment choices.

Prevention of kidney disease is more cost effective than providing treatment of advanced kidney disease and its complications. ${ }^{44}$ Nevertheless, investment in care of the relatively few with ESKD is often prioritised over prevention of development and progression of chronic kidney disease (CKD) in both high income and lower income countries. ${ }^{31,45}$ Investments 
should also be made in conservative and supportive care services for patients with CKD and ESKD as an alternative or complementary treatment and also to provide care in settings where KRT is not an option. ${ }^{31,46}$ Where resources are limited, it may seem preferable to prioritise prevention, or conservative care rather than KRT for those with ESKD. Doing so is likely to produce greater benefits overall for more people, satisfying utilitarian concerns that support a health-maximizing approach to resource allocation. Furthermore, investment in prevention is more likely to produce health benefits for the most disadvantaged populations, thus reducing inequities. However, investment in higher cost services may offer additional benefits to communities, for example by helping to prevent professional "brain drain", and reducing medical travel abroad, thereby strengthening local health systems. On the other hand, it may promote development of a two-tier health system and create internal brain drain by attracting nephrologists to more expensive services that are more financially rewarding. Utility gains should not be the only consideration in priority setting. Communities and individuals affected by these decisions may hold additional values and goals beyond utility gains such as equity in opportunities for care, or have preferences that include provision of some opportunities for higher cost care modalities. Furthermore, if investment in preventive care precludes provision of treatment for ESKD, this can create ethical dilemmas or distress for clinicians who encounter patients with ESKD. Implementing policies that may result in denial of treatment to individuals is difficult for those trained to provide care as needed when a therapeutic relationship is established, especially if high cost services such as haemodialysis are available to those with the ability to pay.

Policy makers and clinicians, together with patients and other stakeholders may need to engage with a range of ethical dilemmas relating to priority setting. Decisions regarding prioritization of preventative, curative, or palliative treatments or KRTs have implications for priority setting in workforce capacity building and training, as well as investment in clinical 
research and novel therapies. For example, training of nurses or allied healthcare fieldworkers may enable more effective provision of primary kidney care in lower income countries. $^{47}$

\section{Avoiding futile or overly burdensome dialysis treatment}

The avoidance of futile treatment is a widely accepted principle in medicine, when futile treatment is understood to mean that applying a particular clinical intervention would not achieve its intended goal or if the disadvantages exceed the benefits. In practice, however, determining when an intervention is likely to be futile is ethically and clinically complex. Patients, their families, and clinicians may disagree on the goals of treatment, the probability of achieving them, the clinical course to such goals, and the threshold for success at which futility may be defined. There may be conflicts between the values, beliefs and preferences of clinicians and patients and their families, particularly within multicultural societies. Incorrect assumptions that a judgement of "futility" with regards to one intervention may preclude alternative treatment (for example dialysis versus comprehensive conservative care) or lead to the abandonment of care more broadly, also complicate discussions of futility.

While it may be easy to determine whether dialysis will be effective in performing specific biochemical clearance functions in a patient with ESKD, such as partially correcting metabolic and homeostatic derangements, estimating their clinical prognosis and determining whether the initiation or continuation of dialysis will support a patient's broader life goals may be more difficult. ${ }^{48}$ For some patients, the benefits of dialysis may be outweighed by harms such as those associated with prolongation of a life the patient judges to be not worth living, or those associated with a brief extension of life at catastrophic financial cost to a patient's family. Dialysis may also increase the symptom burden of dying patients. When 
futile dialysis is provided, this is not only harmful to patients but also may cause distress to families and health professionals and impose significant burdens on health systems. ${ }^{49}$ More tools such as evidence based decision-making tools ${ }^{46,50}$ and the guidelines developed by some national or regional nephrology societies, ${ }^{51-54}$ and efforts to disseminate, encourage and facilitate use of such tools are needed. This would support a more inclusive approach to shared decision-making about dialysis in which health professionals, patients and their families may tease out the goals of care, engage with objective clinical evidence, and formulate a shared understanding of the risks and benefits of available treatment options, including the option of a limited trial of dialysis and the ability of stakeholders to revoke or modify a previous decision. ${ }^{49}$ Tools and training used to support shared decision-making should also engage with relevant legal frameworks and tools to help facilitate resolution of conflict when there is fundamental disagreement between stakeholders as to the appropriate use of life sustaining interventions. Knowledge of relevant legislative frameworks, for example, may help to ensure that physicians and surrogate decision-makers are confident in advocating for treatment or treatment cessation options they judge ethically appropriate, without fear of litigation or criminal prosecution. The establishment of a systematic process for review and resolution of conflicts regarding the potential futility of an intervention, or other aspects of clinical decision-making, may be helpful in managing ethical disagreements. ${ }^{55}$

Decision-making about the potential benefits and risks of treatment options for the individual patient must be carefully distinguished from decision-making about resource allocation. Resource allocation guidelines should exclude the provision of futile treatments so as to avoid wasting healthcare resources. In cases wherein a treatment is not considered futile, but rationing of relevant resources for treatment is unavoidable, patients may be denied access to 
a particular treatment if their need is not considered a priority according to ethically justified resource allocation criteria. The number of people in need of an intervention, and the potential benefits of treatment if it were available, should nevertheless be assessed and documented, and information regarding such cases should be reported to appropriate registries so as to inform and motivate efforts to improve availability of resources.

\section{Supporting shared decision-making about ESKD care}

Although definitions and implementation models of shared decision-making vary, ${ }^{56}$ in many countries shared decision-making is now the standard conceptual approach to clinical decision-making, including in nephrology, especially when choosing kidney replacement therapy or transitioning from dialysis to supportive care. In essence, this approach entails clinicians' respect for patients' right to self governance (autonomy) by treating them as equals and supporting them to make voluntary and informed decisions about their care through a process of dialogue that explores all options for treatment, including conservative or supportive care. This approach is frequently recommended as a strategy to prevent conflicts in end-of-life care and to avoid futile treatment, particularly in the context of dialysis decisions. ${ }^{57,58}$ It is also a valuable tool in preventing coercion or manipulation of patients that may result in unwanted treatment, for example if nephrologists repeatedly question a patient's decision to decline KRT. ${ }^{38}$

There are several potential barriers to use of shared decision-making. First, clinicians may be unfamiliar with this approach or untrained in its use. A recent study of American nephrology trainees highlighted gaps in self-reported preparedness to provide end-of-life care to patients, including lack of familiarity with existing guidelines for shared decision-making. ${ }^{59}$ Providing training to support communication about treatment options and end-of-life decision-making 
in ways that are culturally safe and informed by the realities of the local healthcare and social context is important $60,61,51$

Second, nephrologists may believe that discussions about end-of-life care, transplantation or dialysis modality choice are not a priority within the context of their professional role or should be referred or delegated to other healthcare professionals. ${ }^{60,61}$

Third, some clinicians may believe that discussion of all treatment options for ESKD with some patients may cause unjustifiable harm to patients and their families; for example if they are concerned that promoting living donation may expose potential donors to harm, if they believe that discussing transplantation when there is a low probability of the patient receiving a transplant may cause distress to patients and their families, or if they believe the financial burdens of dialysis may prove catastrophic for patients and their families. ${ }^{22,62}$ Perceived conflicts between physician duties of nonmaleficence and respect for patient autonomy may lead to paternalistic practices with harmful consequences. Failure to disclose information to patients and their families about options for care (and their risks and benefits) that are within the reach of local possibilities shows a lack of respect for the autonomy of patients and their families, and disempowers them from advocating to address barriers to care. It may also lead to poorer decision-making, and undermine trust in therapeutic relationships, particularly as such information may be discovered through other means. ${ }^{63}$

\section{Reducing the cost of dialysis care without compromising quality of care}

Efforts to reduce the costs of dialysis care are especially important in contexts where costs frequently preclude access. In Asia and Africa, for example, the majority of people with ESKD cannot afford dialysis. ${ }^{2}$ Health policy makers and insurance providers may establish 
policies aimed at reducing costs of care that may pose little threat to patient outcomes or quality of care, for example by prioritising peritoneal dialysis. ${ }^{64}$ However, some strategies that may reduce costs or enable more patients to access dialysis, such as reducing dialysis hours, may negatively impact on outcomes and thus pose ethical dilemmas for clinicians involved in decision-making. Conversely, efforts to improve the quality of care for some people may reduce access for others. For example, providing more frequent dialysis (three times rather than twice a week) may reduce the number of patients who can access treatment in the context of limited availability. ${ }^{66}$ Larger, centrally located dialysis centres with consolidated expertise may provide better outcomes than smaller clinics. ${ }^{66}$ However the latter may provide better access to care for patients living in remote areas. Furthermore, the relationships, behaviours and decisions of multiple stakeholders may significantly influence the costs of resources and the financial returns available for individuals and institutions. Stakeholders and potential financial beneficiaries may include governments, healthcare providers and professionals, and manufacturers of dialysis system components and drugs, or transport companies.

For example, the cost of dialysis system components may be more readily controlled by health authorities when these are manufactured within the country, and the costs of providing dialysis care may be partially offset within a country by the benefits of the local dialysis economy, including taxes paid by service providers and consumers and local jobs created. On the other hand, perverse incentives may encourage disproportionate expenditure, for example if nephrologists are paid high fees for providing dialysis care which may encourage over servicing or discourage referral of patients for transplantation or conservative care. Finally, in the context of a 'fixed' payment for dialysis, there is the risk that cost-saving measures may 
compromise the quality of care in order to maximise profits, for example by allotting the same budget to an increased patient volume so that consultation time per patient is reduced.

Ethical analysis may assist clinicians and policy makers, as well as community stakeholders, in making decisions that will promote better care and patient outcomes without exacerbating or creating inequities of access or quality of care, and in managing potential conflicts of interest in decision-making. In addition, ethical guidance is needed to ensure that fear of compromising quality of care does not lead to avoidance of care altogether. In some contexts, compromises may be necessary; clinical standards considered best practice and outcomes for dialysis care in some countries or communities may not be an appropriate measure of success in another, particularly when compared with broader social and healthcare goals and standards. Standards deemed appropriate at one moment may be later challenged based on new evidence. It is the responsibility of the nephrological community to strive to promote therapeutic options that are less costly for society and to advocate for research and development of affordable treatment modalities. Finally, ethical guidance may be needed to support decision-making when tensions arise between different ethical concerns. For example, if all patients want higher quality care but only some are able to pay for such care, patient autonomy and concern for health equity are in tension. Furthermore, if informing patients of compromises in care may cause anxiety, distress or avoidance of care, then respect for autonomy and duties of beneficence and nonmaleficence are in tension.

\section{Preventing organ trafficking and transplant "tourism"}

As many as $10 \%$ of kidney transplants performed worldwide each year are estimated to involve organ trafficking, in which case organs are treated as a saleable commodity, or transplant "tourism", in which case patients travel internationally to purchase an organ 
transplant in circumstances that involve organ trafficking or undermine national selfsufficiency in transplantation in the destination country. ${ }^{67}$ These practices cause great harm to vulnerable people who are forced to sell a kidney, and to their families and communities, ${ }^{68-70}$ and also endanger recipients of such kidneys. ${ }^{71-73}$ Organ trafficking and transplant "tourism" have also fuelled unethical practices such as the execution of prisoners for organ procurement and sale in China, and the prioritisation of wealthy foreign patients in allocation of deceased donor organs. ${ }^{74,75}$

Organ trafficking, which includes procurement and use of organs from prisoners or others who are coerced to provide organs for transplantation, ${ }^{76}$ undermines trust in legitimate donation and transplantation programs, and exacerbates inequities in donation and transplantation. While ethical guidance is available at the level of broad principles established by the international community through the World Health Organization ${ }^{77}$ and the Declaration of Istanbul Custodian Group (DICG) ${ }^{76,78}$ health professionals must nevertheless grapple with several complex ethical issues if they are to assist in preventing organ trafficking. ${ }^{79}$ Ethical dilemmas may arise for nephrologists in managing patients who plan to travel abroad for an illegal transplant, who return after traveling abroad for a transplant that is suspected to involve trafficking, or whom they suspect to be involved in organ trafficking domestically. ${ }^{80-}$ ${ }^{83}$ These dilemmas often involve tensions between duties of care to patients and obligations to prevent harm to others. For example, physician refusal to facilitate travel abroad for transplantation when organ trafficking is suspected, e.g., by declining to perform clinical investigations requested by professionals in the destination transplant centre, may also delay or prevent patients from obtaining a transplant. While this is consistent with duties to prevent harm to one's own patient, given the clinical, financial and legal risks associated with travel for commercial transplantation, in many cases the overriding justification may be the duty to 
prevent harm to others. Alternatively, reporting cases of suspected organ trafficking in order to inform actions against health professionals or others involved in transplant-related crimes may involve a breach of patient confidentiality. ${ }^{81,82}$ More work is needed to support management of ethical issues relating to trafficking or tourism in the local context, for example by establishing policy or legislation to govern and facilitate reporting of suspected organ trafficking cases in a manner that protects vulnerable kidney sellers and potentially patient privacy while enabling collection of data that may inform efforts to combat trafficking. ${ }^{81,82}$ Health professionals may also assist in preventing organ trafficking and transplant tourism by providing education and counselling to patients who may be at risk of traveling abroad to purchase a kidney transplant. ${ }^{76,79}$

\section{Evaluating the risks and outcomes of living kidney donation}

A growing body of evidence regarding the long term physical risks of living kidney donation within specific populations has enabled better risk assessment and hence in theory improved the quality of informed decision-making about living donation. ${ }^{84}$ However, tools for evaluating and communicating risk to potential donors are developed for and informed by research in specific donor populations and may thus be less relevant to other populations. ${ }^{25,85}$ Emerging information about the psychosocial outcomes of donors and those who are declined as donors is also contributing to risk assessment and informed decision-making around the world. ${ }^{84-86}$ Clinicians and patients may experience difficulty in communicating and understanding risks, for example when distinguishing between relative and absolute risks and when recognizing risks that are modifiable. Tools used in other healthcare fields to improve communication about risks may also help to support informed decision-making about donation. ${ }^{87}$ Clinicians must grapple with the ethical dilemma of determining when the risks are sufficiently great to justify refusing a willing donor. ${ }^{25,88}$ Tensions between respecting the 
autonomy of a prospective donor, and preventing avoidable harm to donors may cause ethical anxiety for clinicians. ${ }^{89}$

Despite the evidence available, tailoring risk management to an individual prospective living donor remains a highly subjective process bound by considerable uncertainty. This may especially be the case in LMICs in which access to allied health staff and other resources to support evaluation of psychosocial aspects of living donation may be limited. Nephrologists with responsibility for assessing prospective donors may lack expertise and experience in performing psychosocial evaluation, and/or may have limited time to conduct such an evaluation. It is particularly challenging to evaluate risks and consider these in the context of the potential benefits of successful transplantation to both the recipient and the donor, while respecting the important role of the donor in judging the proportionality of those risks and benefits. ${ }^{90}$ More ethical guidance tools should be developed that can assist in reducing ethical uncertainty and distress in contexts where clinical decision-making is not self-evident. ${ }^{91,92}$

\section{Addressing the ethical implications of genetic kidney diseases}

Emerging information about the role of genetic and epigenetic factors influencing kidney disease $^{93}$ will expand the range of ethical issues confronting clinicians and patients. As is the case with genomics in medicine more generally, increased use of genetic information in the investigation and management of kidney disease is associated with potential benefits for patient autonomy and health but also with risks. ${ }^{93}$ Use of genetic testing and genetic information may endanger patient privacy and confidentiality, and has the potential to harm individuals, families and communities, for example by increasing insurance premiums, creating social stigma or facilitating discrimination in employment. When a person is diagnosed with kidney disease, information about the aetiology of their condition may be 
relevant to their genetic relatives. Ethical issues may arise relating to obligations to disclose information to others, ${ }^{94}$ and/or obligations to protect others from unwanted information about their genetic risk of disease. ${ }^{95}$ The ethical duties of the nephrologist in supporting disclosure may be unclear. ${ }^{96}$ Issues may also arise in the context of decision-making about procreation by an affected individual or couple..$^{97}$ Greater understanding of the genetic and epigenetic factors influencing kidney disease is also impacting risk assessment and treatment decisionmaking, ${ }^{98}$ including risk assessment of potential living kidney donors wishing to donate to a genetic relative. ${ }^{99}$

In LMICs the unavailability of tools for genetic diagnosis and/or counselling may undermine the quality of care available for patients and increase inequities in access to care. Inability to identify a genetic cause when it exists may lead to inappropriate treatment and waste of scarce resources which could be avoided with better diagnosis of disease aetiology. To ensure that patients have access to appropriate care and are supported to make informed decisions about their care and management of their genetic information, nephrologists require training and continuing education in this field not only from a clinical and scientific perspective but also with regards to the ethical implications of genetic kidney diseases. Nephrologists should also advocate on behalf of patients for access to resources such as genetic testing and counselling services.

\section{Advocating responsibly for kidney health}

Advocacy by professionals in collaboration with patient organizations and individuals is vital in promoting awareness and understanding of kidney health. In some contexts it may also be influential in gaining funding for research or care services from governmental, industry or 
philanthropic sources. Several ethical issues may arise in the context of advocacy efforts for kidney health.

First, there is growing awareness of ethical concerns regarding conflicts of interest in relationships between industry and professional medical societies and patient advocacy organizations. ${ }^{100,101}$ As yet, there has been no research exploring ethical issues of advocacy specifically in the context of kidney care. Inadequately managed conflicts of interest may undermine the integrity of research and clinical practice guidelines.

Second, factors that may influence the efficacy of advocacy efforts and fundraising appeals may also influence decision-making by organizations regarding which diseases, populations or therapies to prioritise for advocacy, potentially creating or sustaining inequities in kidney care. Such factors may include lack of evidence or knowledge regarding the impact of particular diseases in specific populations, costs of care, stigma, political bias and perceived severity of need for care in a particular population. ${ }^{102-104}$

Third, physicians, patient organizations and others may exploit - intentionally or not vulnerable patients or communities in advocacy efforts. Use of personal narratives is an established method of soliciting public donations to charities and promoting kidney donation. ${ }^{105-6}$ Problematic practices in kidney health advocacy may include soliciting financial donations from wealthy patients, and asking patients, their families or communities to publicly share stories of personal tragedy or disease that may be helpful in raising awareness or attracting funding. ${ }^{107,108}$ The representation of individuals and communities in advocacy materials may expose people to stigmatisation, or may violate privacy if individuals feel unable to decline. Ensuring that therapeutic relationships are not exploited in 
this way, and protecting individuals such as children who may be unable to choose autonomously whether to participate in advocacy efforts is essential. Establishing ethical guidelines to govern advocacy efforts would help to address such concerns, for example by setting standards for transparency, consent, and management of conflicts of interest.

\section{Managing conflicts of interest in nephrology}

As noted in several of the issues explored above, conflicts of interest on the part of various stakeholders, including health professionals and patient and advocacy organizations, may influence decision-making and undermine care and equity of access to care in the context of kidney disease. In particular, individual and organizational financial interests may influence the goals and priorities of patients, clinicians, healthcare providers and policy makers and require careful management. The financial impact of kidney disease on societies, healthcare systems, patients and their families is substantial. ${ }^{109-111}$ Reluctance to acknowledge and engage with financial interests explicitly when setting goals of care or policy not only undermines transparency but also may have harmful consequences. The disproportionate investment in dialysis, for example, without comparable development of transplantation and preventive kidney health programs may hamper efforts to implement sustainable solutions to the problem of kidney disease.

Conflicts of interest can also impact on the development of practice guidelines. ${ }^{112,113}$ Management of conflicts of interest requires clear processes and policies for use in particular contexts, and specific attention to broader contextual factors which may underpin interests or make avoidance of competing interests difficult. For example, physicians' financial interests may be embedded in the structure of health payment systems such that their influence on clinical decision-making is readily overlooked. 
Further work on the ethical implications of conflicts of interest in nephrology is needed, particularly with respect to determination of situations in which conflicts of interest should preclude participation by individuals or organizations in decision-making. ${ }^{112}$ Popular management strategies such as disclosure of conflicts are of limited efficacy, ${ }^{114}$ and do not address the inherent ethical concerns regarding the impact of bias in decision-making, clinical judgement or scientific analysis. In addition, exploration of potential conflicts of interest within families making decisions regarding treatment of ESKD and management strategies to address these would be helpful. For example, clinicians may face difficulty when dealing with prospective living related donors who may be emotionally and/or financially dependent on prospective transplant recipients and with families for whom decisions about initiation or cessation of dialysis may have significant financial consequences.

\section{Taking action to address ethical issues in nephrology}

This paper presents only a brief sketch of several broad themes of ethical concern in nephrology. Each challenge described comprises a range of complex issues that may have specific implications in the context of particular populations or healthcare systems. Each issue deserves an indepth analysis by expert groups and requires collaborative action by nephrology communities including stakeholders such as policymakers and patients to develop tools, training modules and other resources that may guide decision-making and support ethical practice. Having highlighted the challenges, the ASN-ERA-EDTA-ISN Joint Working Group on Ethical Issues in Nephrology will next encourage members of the three societies and partner organisations to initiate in-depth discussions about these issues with the aim of supporting the development of tools to guide ethical decision-making in clinical practice, adapting these tools to suit local contexts, building capacity amongst nephrologists to recognise and respond to ethical challenges, and making routine the application of these tools 
and principles to health policy, clinical practice and research. A proposed plan of action by the Working Group is outlined in Box 2.

Finally, the authors call on health professional colleagues, members of patient communities, policymakers, ethicists, health economists and social scientists to take action in exploring and addressing ethical issues in nephrology that are of concern in their local context. While ethical considerations in research and clinicial decision making are often noted in passing, we believe that giving a more prominent place to engagement with ethical issues is necessary. The ASN,-ERA-EDTA-ISN Joint Working Group is eager to establish a sustainable program of work that will enable regular review of issues and resources that may require updating in the light of emerging evidence or contextual changes that influence the manifestation and management of ethical issues. The societies are also committed to working in collaboration with other regional and national societies of nephrology, in order to draw on the wealth of global expertise and experience and to ensure that the needs, values and preferences of the global community inform the development of a global bank of resources supporting ethical practice in kidney health. 
Box 2 - Action plan for the ASN -ERA-EDTA-ISN Joint Working Group on ethical issues in nephrology

\section{Formation of working groups to address the 10 challenges}

Convene multidisciplinary, multinational working groups including patient stakeholders who will be responsible for ongoing work on each challenge that will involve exploration of issues and development of tools including educational resources.

2. Development of a global multidisciplinary network and resource bank in nephrology ethics

An email list serve and website page will be established to facilitate networking, for example to assist people and organizations looking for collaborators with relevant expertise, and to communicate information about opportunities for collaboration. The website will host a curated set of resources of relevance including ethical analysis of specific issues, guidelines, educational tools etc.

\section{Establish dedicated streams for nephrology ethics in society conferences}

In order to give more prominence to existing work on ethics in kidney health, to highlight the importance of ethics to health professionals and to facilitate development of collaborations on new work on emerging issues in nephrology, dedicated space for discussion of ethical topics will be established in society conference programmes.

\section{Declaration of interests:}

The authors have no conflicts of interest to disclose. 


\section{References:}

1. Jha, V., et al. Chronic kidney disease: global dimension and perspectives. Lancet. 382, 260-272 (2013).

2. Liyanage, T., et al. Worldwide access to treatment for end-stage kidney disease: a systematic review. Lancet. 385, 1975-1982 (2015).

3. Parker, J.C. Cherry picking in ESRD: an ethical challenge in the era of pay for performance. Semin. Dial. 24, 5-8 (2011).

4. Rodriguez, R.A. Dialysis for undocumented immigrants in the United States. $A d v$ Chronic Kidney Dis. 22, 60-65 (2015).

5. Saunders, M.R., Lee, H., Maene, C., Schuble, T. \& Cagney, K.A. Proximity does not equal access: racial disparities in access to high quality dialysis facilities. J. Racial Ethn. Health Disparities. 1, 291-299 (2014).

6. White, S.L., Chadban, S.J., Jan, S., Chapman, J.R., \& Cass, A. How can we achieve global equity in provision of renal replacement therapy?. Bull. World Health Organ. 86, 229-37 (2008).

7. Kahrass, H., Strech, D., \& Mertz, M. The full spectrum of clinical ethical issues in kidney failure. Findings of a systematic qualitative review. PloS one. 3, e0149357 (2016).

8. Jha, V., et al. Ethical issues in dialysis therapy. Lancet. 389, 1851-6 (2017).

9. Davison, S.N. \& Holley J.L. Ethical issues in the care of vulnerable chronic kidney disease patients: the elderly, cognitively impaired, and those from different cultural backgrounds. Adv. Chronic Kidney Dis. 15,177-85 (2008).

10. Davison, S.N. The ethics of end-of-life care for patients with ESRD. Clin. J. Am. Soc. Nephrol. 7, 2049-57 (2012). 
11. Brennan, F. \& Brown, M. An ethical approach to dialysis-An alliance of nephrology, palliative medicine and ethics. Q. J. Med. 106, 397-40 (2013).

12. Muthalagappan, S., Johansson, L., Kong, W.M, \& Brown, E.A. Dialysis or conservative care for frail older patients: ethics of shared decision-making. Nephrol. Dial. Transplant. 28, 2717-22 (2013)

13. Ozar, D.T., et al. Nephrologists' professional ethics in dialysis practices. Clin. J. Am. Soc. Nephrol. 8, 840-844 (2013).

14. Etheredge, H. \& Paget, G. Ethics and rationing access to dialysis in resource-limited settings: the consequences of refusing a renal transplant in the South African state sector. Dev. World Bioeth. 15, 233-240 (2015).

15. Shooter, M., \& Watson, A. The ethics of withholding and withdrawing dialysis therapy in infants. Pediatr. Nephrol. 14, 347-51 (2000).

16. Lantos, J.D. \& Warady, B.A. The evolving ethics of infant dialysis. Pediatr. Nephrol. 28, 1943-7 (2013).

17. Fauriel, I., et al. Decisions concerning potentially life-sustaining treatments in paediatric nephrology: a multicentre study in French-speaking countries. Nephrol. Dial. Transplant. 2004 Feb 19;19(5):1252-7.

18. Maurizi, J.B., Moreaud, O., Palacin, P., Truche, A.S. \& Zaoui, P. Ethics consultation unit in nephrology (UCEN): review of 10 years of operation in the Grenoble area. Nephrol. Ther. 9, 222-7 (2013).

19. Redman, B.K., Hill, M.N. \& Fry, S.T. Ethical conflicts reported by certified nephrology nurses (CNNs) practicing in dialysis settings. ANNA J. 24, 23-34 (1997).

20. Akbar, S., \& Moss, A.H. The ethics of offering dialysis for AKI to the older patient: Time to re-evaluate?. Clin. J. Am. Soc. Nephrol. 9, 1652-1656 (2014). 
21. Butler, C.R., Mehrotra, R., Tonelli, M.R., \& Lam, D.Y. The evolving ethics of dialysis in the United States: a principlist bioethics approach. Clin. J. Am. Soc. Nephrol. 11, 704-709 (2016).

22. Luyckx, V.A., Miljeteig, I., Ejigu, A.M., \& Moosa M.R. Ethical challenges in the provision of dialysis in resource-constrained environments. Semin. Nephrol. 37, 273286 (2017).

23. Hirsch, D.J., West, M.L., Cohen, A.D. \& Jindal, K.K. Ethical And Moral Issues In Nephrology: Experience With Not Offering Dialysis to Patients With a Poor Prognosis. Am. J. Kidney Dis. 23, 463-6 (1994).

24. Rabetoy, C.P., \& Bair, B.C. Nephrology nurses' perspectives on difficult ethical issues and practice guideline for shared decision making. Nephrol. Nurs. J. 34, 599607 (2007).

25. Reese, P.P., Boudville, N., \& Garg, A.X. Living kidney donation: outcomes, ethics, and uncertainty. Lancet. 385, 2003-13 (2015).

26. Gordon, E.J. Informed consent for living donation: a review of key empirical studies, ethical challenges and future research. Am. J. Transplant. 12, 2273-80 (2012).

27. Maizlin, Z.V., Barnard, S.A., Gourlay, W.A., \& Brown, J.A. Economic and ethical impact of extrarenal findings on potential living kidney donor assessment with computed tomography angiography. Transplant. Int. 20, 338-42 (2007).

28. Wiles, K.S., et al. Pre-pregnancy counselling for women with chronic kidney disease: a retrospective analysis of nine years' experience. BMC Nephrol. 16, 28 (2015).

29. Davison, S.N. Ethical considerations regarding pregnancy in chronic kidney disease. Adv. Chronic Kidney Dis. 14, 206-11 (2007).

30. McDougall, R. Reviewing Literature in Bioethics Research: Increasing Rigour in Non-Systematic Reviews. Bioethics. 29, 523-8 (2015). 
31. Harris, D. C., et al. Increasing access to integrated ESKD care as part of universal health coverage. Kidney Int. 95, S1-S33 (2019).

32. Whitehead, M. The concepts and principles of equity and health. Health Promot. Int. 6, 217-228 (1991).

33. Anderson K., et al. If you can't comply with dialysis, how do you expect me to trust you with transplantation? Australian nephrologists' views on indigenous Australians' 'non-compliance'and their suitability for kidney transplantation. Int. J. Equity Health. 11, 21 (2012).

34. Stewart, D.E., et al. Measuring and monitoring equity in access to deceased donor kidney transplantation. Am. J. Transplant. doi.org/10.1111/ajt.14922 (2018).

35. Patzer, R.E., et al. Variation in dialysis facility referral for kidney transplantation among patients with end-stage renal disease in Georgia. JAMA. 314, 582-9 (2015).

36. Shaikh, M., et al. Utilization, costs, and outcomes for patients receiving publicly funded hemodialysis in India. Kidney Int. 94, 440-5 (2018).

37. Rutecki, G.W., Cugino, A., Jurjoura, D., Kilner, J.F., \& Whittier, F.C. Nephrologists' subjective attitudes towards end-of-life issues and the conduct of terminal care. Clin. Nephrol. 48, 173-180 (1997).

38. Ladin, K., Smith, A.K. Active medical management for patients with advanced kidney disease. JAMA Intern Med. 179, 313-5 (2019).

39. Boulware, L.E., Wang, V., Powe, N.R. Improving Access to Kidney Transplantation: Business as Usual or New Ways of Doing Business?. JAMA. 322, 931-3 (2019).

40. Van Biesen, W., Vanholder, R., Ernandez, T., Drewniak, D., \& Luyckx, V. Caring for migrants and refugees with end-stage kidney disease in Europe. Am. J. Kidney Dis.

71, 701-9 (2018). 
41. Luyckx, V.A., Bello, A.K., \& Naicker, S. Developing Nephrology Programs in Low Resource Settings. In Chronic Kidney Disease in Disadvantaged Populations (ed. Garcia-Garcia, G., Agodoa, L.Y., \& Norris, K.C.) 273-289 (Academic Press, 2017).

42. Ducharlet, K., Philip, J., Gock, H., Brown, M., Gelfand, S.L., Josland, E.A. and Brennan, F. Moral Distress in Nephrology: Perceived Barriers to Ethical Clinical Care. Am. J. Kidney Dis. (2019).

43. Tong A., et al. Research priority setting in kidney disease: a systematic review. Am. J. Kidney Dis. 65, 674-83 (2015).

44. Vanholder, R., et al. Reducing the costs of chronic kidney disease while delivering quality health care: a call to action. Nat. Rev. Nephrol. 13, 393 (2017).

45. Van Der Tol A., Lameire N., Morton R.L., Van Biesen W., \& Vanholder R. An international analysis of dialysis services reimbursement. Clin. J. Am. Soc. Nephrol.. 14, 84-93 (2019).

46. Dusseux, E., et al. A simple clinical tool to inform the decision-making process to refer elderly incident dialysis patients for kidney transplant evaluation. Kidney Int. 88, 121-9 (2015).

47. Osman, M.A., et al. Global nephrology workforce: gaps and opportunities toward a sustainable kidney care system. Kidney Int. Suppl. 8, 52-63 (2018).

48. Hussain, J.A., Flemming, K., Murtagh, F.E., Johnson, M.J. Patient and health care professional decision-making to commence and withdraw from renal dialysis: a systematic review of qualitative research. Clin. J. Am. Soc. Nephrol. 10, 1201-1215 (2015).

49. Rinehart, A. Beyond the futility argument: the fair process approach and time-limited trials for managing dialysis conflict. Clin. J. Am. Soc. Nephrol. 8,2000-6 (2013). 
50. Morton, R. Do Dialysis Decision Aids Improve Treatment Decision-Making?. Peritoneal Dialysis International. 36, 359-61 (2016).

51. Galla, J.H. Clinical practice guideline on shared decision-making in the appropriate initiation of and withdrawal from dialysis. J. Am. Soc. Nephrol. 11, 1340-2 (2000).

52. Brown, M.A., et al. ANZSN renal supportive care guidelines. Nephrology. 18, 401-54 (2013).

53. García-Llana, H., Bajo, M.A., Barbero, J., Selgas, R., Del Peso, G. The Communication and Bioethical Training (CoBiT) Program for assisting dialysis decision-making in Spanish ACKD units. Psychol. Health Med. 22: 474-82 (2017).

54. Farrington, K., et al. 2017. Clinical Practice Guideline on management of older patients with chronic kidney disease stage $3 \mathrm{~b}$ or higher $(\mathrm{eGFR}<45 \mathrm{~mL} / \mathrm{min} / 1.73 \mathrm{~m} 2)$ : a summary document from the European Renal Best Practice Group. Nephrol. Dial. Transplant. 32, 9-16 (2017).

55. Moss, A.H. Revised dialysis clinical practice guideline promotes more informed decision-making. Clin. J. Am. Soc. Nephrol. 5, 2380-3 (2010).

56. Makoul, G., Clayman, M.L. An integrative model of shared decision making in medical encounters. Patient Educ. Couns. 60, 301-12 (2006).

57. Renal Physicians Association. Shared Decision-Making in the Appropriate Initiation of and Withdrawal From Dialysis: Clinical Practice Guideline. 2nd ed. Rockville, MD. Available at: www.renalmd.org. (2010).

58. Williams, A.W., et al. Critical and honest conversations: the evidence behind the “Choosing Wisely" campaign recommendations by the American Society of Nephrology. Clin. J. Am. Soc. Nephrol. 7, 1664-72 (2012). 
59. Combs, S.A., Culp, S., Matlock, D.D., Kutner, J.S., Holley, J.L., Moss, A.H. Update on end-of-life care training during nephrology fellowship: a cross-sectional national survey of fellows. Am. J. Kidney Dis. 65, 233-9 (2015).

60. Ladin, K., et al. Characterizing approaches to dialysis decision making with older adults: a qualitative study of nephrologists. Clin. J. Am. Soc. Nephrol. 13, 1188-96 (2018).

61. Bansal, A.D., \& Schell, J.O. Strategies to address clinician hesitancy toward conservative care. Nephrol. Dial. Transplant. Epub. Nov 1. gfy339, https://doi.org/10.1093/ndt/gfy339 (2018).

62. Miljeteig, I., et al. Financial risk protection at the bedside: How Ethiopian physicians try to minimize out-of-pocket health expenditures. PloS One. 14, e0212129 (2019).

63. Wong, S.P., McFarland, L.V., Liu, C.F., Laundry, R.J., Hebert, P.L., O’Hare, A.M. Care practices for patients with advanced kidney disease who forgo maintenance dialysis. JAMA Intern. Med. 179, 305-13 (2019).

64. Li, P.K., Chow, K.M. Peritoneal dialysis-first policy made successful: perspectives and actions. Am. J. Kidney Dis. 62, 993-1005 (2013).

65. Savla, D., Chertow, G.M., Meyer, T., \& Anand, S. Can twice weekly hemodialysis expand patient access under resource constraints?. Hemodial. Int. 21, 445-52 (2017).

66. Plantinga L.C., Fink N.E., Finkelstein F.O., Powe N.R., \& Jaar B.G. Association of peritoneal dialysis clinic size with clinical outcomes. Perit. Dial. Int. 29, 285-91 (2009).

67. Shimazono, Y. The state of the international organ trade: a provisional picture based on integration of available information. Bull. World Health Organ. 85, 955-62 (2007). 68. Naqvi S.A., Ali B., Mazhar F., Zafar M.N., \& Rizvi S.A. A socioeconomic survey of kidney vendors in Pakistan. Transpl. Int. 20, 934-9 (2007). 
69. Columb, S. Excavating the organ trade: An empirical study of organ trading networks in Cairo, Egypt. Br. J. Criminol. 57, 1301-21 (2016).

70. Goyal, M., Mehta, R.L., Schneiderman, L.J., \& Sehgal, A.R. Economic and health consequences of selling a kidney in India. JAMA. 288, 1589-93 (2002).

71. Anker, A.E., \& Feeley, T.H. Estimating the risks of acquiring a kidney abroad: a meta-analysis of complications following participation in transplant tourism. Clin. Transplant. 26, E232-41 (2012).

72. Canales, M.T., Kasiske, B.L., \& Rosenberg, M.E. Transplant tourism: outcomes of United States residents who undergo kidney transplantation overseas. Transplantation. 82, 1658-61 (2006).

73. Prasad, G.R., et al. Commercial kidney transplantation is an important risk factor in long-term kidney allograft survival. Kidney Int. 89, 1119-24 (2016).

74. Danovitch, G.M., et al. Organ trafficking and transplant tourism: the role of global professional ethical standards - the 2008 Declaration of Istanbul. Transplantation 95, 1306-12 (2013).

75. Danovitch, G.M., Shapiro, M.E., \& Lavee, J. The use of executed prisoners as a source of organ transplants in China must stop. Am. J. Transplant. 11, 426-8 (2011).

76. Martin, D.E., et al. Strengthening global efforts to combat organ trafficking and transplant tourism: implications of the 2018 edition of the Declaration of Istanbul. Transplant. Direct. 5, e433 (2019).

77. World Health Organization. WHO guiding principles on human cell, tissue and organ transplantation. Transplantation. 90, 229-33 (2010).

78. Martin, D.E., et al. A new edition of the Declaration of Istanbul: updated guidance to combat organ trafficking and transplant tourism worldwide. Kidney Int. 95, 757-9 (2019). 
79. Domínguez-Gil, B., López-Fraga, M., Muller, E., \& Gill, J.S. The key role of health professionals in preventing and combating transplant-related crimes. Kidney Int. 92, 1299-302 (2017).

80. Domínguez-Gil, B., et al. Management of patients who receive an organ transplant abroad and return home for follow-up care: recommendations from the Declaration of Istanbul Custodian Group. Transplantation. 102, e2-9 (2018).

81. Ambagtsheer, F., Van Balen, L.J., Duijst-Heesters, W.L., Massey, E.K., \& Weimar, W. Reporting organ trafficking networks: a survey-based plea to breach the secrecy oath. Am. J. Transplant. 15, 1759-67 (2015).

82. Martin, D.E., et al. Prevention of transnational transplant-related crimes-What more can be done?. Transplantation. 100, 1776-84 (2016).

83. Caulfield, T., et al. Trafficking in human beings for the purpose of organ removal and the ethical and legal obligations of healthcare providers. Transplant Direct. 2, e60 (2016).

84. Lentine, K.L., Lam, N.N., Segev, D.L. Risks of Living Kidney Donation: Current State of Knowledge on Outcomes Important to Donors. Clin. J. Am. Soc. Nephrol. 14, 597-608 (2019).

85. Steiner, R.W. "You can’t get there from here": Critical obstacles to current estimates of the ESRD risks of young living kidney donors. Am. J. Transplant 19, 32-36 (2019).

86. Dew, M.A., \& Jacobs, C.L. Psychosocial and socioeconomic issues facing the living kidney donor. Adv. Chronic Kidney Dis. 19, 237-243 (2012).

87. Fagerlin, A., Zikmund-Fisher, B.J., Ubel, P.A. Helping patients decide: ten steps to better risk communication. J. Natl. Cancer Inst. 103, 1436-43 (2011).

88. Reese, P.P., et al. Outcomes for individuals turned down for living kidney donation. Clin. Transplant. 32, e13408 (2018) 
89. Tong, A., Chapman, J.R., Wong, G., Craig, J.C. Living kidney donor assessment: challenges, uncertainties and controversies among transplant nephrologists and surgeons. Am. J. Transplant. 13, 2912-23 (2013).

90. Thiessen, C., Gordon, E.J., Reese, P.P., \& Kulkarni, S. Development of a donorcentered approach to risk assessment: Rebalancing nonmaleficence and autonomy. Am. J. Transplant. 15, 2314-23 (2015).

91. Abramowicz, D., et al. European Renal Best Practice Guideline on kidney donor and recipient evaluation and perioperative care. Nephrol. Dial. Transplant. 30, 1790-7 (2014).

92. Lentine, K.L., et al. Summary of Kidney Disease: Improving Global Outcomes (KDIGO) clinical practice guideline on the evaluation and care of living kidney donors. Transplantation. 101, s7-s105 (2017).

93. Witasp, A., et al. How can genetics and epigenetics help the nephrologist improve the diagnosis and treatment of chronic kidney disease patients?. Nephrol. Dial. Transplant. 29, 972-80 (2014).

94. Dugan, R.B., et al. Duty to warn at-risk relatives for genetic disease: genetic counselors' clinical experience. Am. J. Med. Genet. C. Semin. Med. Genet. 119, 27-34 (2003)

95. Husted, J. Autonomy and a right not to know. In The right to know and the right not to know: genetic privacy and responsibility. (ed. Chadwick, R., Levitt, M., \& Shickle, D.) 24-37 (Cambridge University Press, Cambridge, 2014)

96. Forrest, L.E., Delatycki, M.B., Skene, L., \& Aitken, M. Communicating genetic information in families-a review of guidelines and position papers. Eur. J. Hum. Genet. 15, 612-8 (2007). 
97. De Rechter S., et al. Clinicians' attitude towards family planning and timing of diagnosis in autosomal dominant polycystic kidney disease. PloS One. 12, e0185779 (2017).

98. Bierzynska, A., et al. Genomic and clinical profiling of a national nephrotic syndrome cohort advocates a precision medicine approach to disease management. Kidney Int. 91, 937-47 (2017).

99. Riella, L.V. \& Sheridan, A.M. Testing for high-risk APOL1 alleles in potential living kidney donors. Am. J. Kidney Dis. 66, 396-401 (2015).

100. McCoy, M.S., Carniol, M., Chockley, K., Urwin, J.W., Emanuel, E.J., Schmidt, H. Conflicts of interest for patient-advocacy organizations. N. Engl. J. Med. 376, 880-5 (2017).

101. Nissen, S.E. Conflicts of interest and professional medical associations: progress and remaining challenges. JAMA. 317, 1737-8 (2017).

102. Shiffman, J. Donor funding priorities for communicable disease control in the developing world. Health Policy Plan. 21, 411-20 (2006).

103. Esser, D.E., Bench, K.K. Does global health funding respond to recipients' needs? Comparing public and private donors' allocations in 2005-2007. World Dev. 39, 1271-80 (2011).

104. Body, A., Breeze, B. What are 'unpopular causes' and how can they achieve fundraising success?. Int. J. Nonprofit Volunt. Sect. Mark. 21, 57-70 (2016).

105. Merchant, A., Ford, J.B., Sargeant, A. Charitable organizations' storytelling influence on donors' emotions and intentions. J. Bus. Res. 63, 754-62 (2010).

106. Novogrodsky, E., et al. The role of media in non-directed (altruistic) living kidney donation. Health Commun. 34, 259-67 (2019). 
107. Macauley, R. The ethics of cultivated gratitude. HEC Forum 26, 343-348 (2014).

108.Reid, L. Ethical issues in health philanthropy. Healthc. Manage. Forum 30, 298-301 (2017).

109. Davison, S.N., et al. Executive summary of the KDIGO Controversies Conference on Supportive Care in Chronic Kidney Disease: developing a roadmap to improving quality care. Kidney Int. 88, 447-59 (2015).

110. Tucker, P.S., Kingsley, M.I., Morton, R.H., Scanlan, A.T., Dalbo, V.J. The increasing financial impact of chronic kidney disease in Australia. Int. J. Nephrol. dx.doi.org/10.1155/2014/120537 (2014).

111. Turchetti, G., et al. The social cost of chronic kidney disease in Italy. Eur. $J$. Health Econ. 18, 847-58 (2017).

112. Coyne, D. Influence of industry on renal guideline development. Clin. J. Am. Soc. Nephrol. 2, 3-7 (2007).

113. Ransohoff, D.F., Pignone, M., Sox, H.C. How to decide whether a clinical practice guideline is trustworthy. JAMA. 309, 139-40 (2013).

114. Loewenstein, G., Sah, S., Cain, D.M. The unintended consequences of conflict of interest disclosure. JAMA. 307, 669-70 (2012). 